\title{
Synthesis and characterization of polymeric films and nanotubule nets used to assemble selective sensors for nitrite detection in drinking water
}

\author{
Vanessa Biagiotti*, Federica Valentini, Emanuela Tamburri, \\ Maria Letizia Terranova, Danila Moscone, Giuseppe Palleschi
}

Università degli studi di Roma Tor Vergata, Dipartimento di Scienze e Tecnologie Chimiche, via della Ricerca Scientifica 1, 00133 Rome, Italy

Received 16 March 2006; received in revised form 18 May 2006; accepted 22 May 2006

Available online 27 June 2006

\begin{abstract}
Platinum electrodes were modified by electropolymerized films and polymer nanotubule nets and were applied to nitrite detection in drinking water. Several analytical parameters were investigated such as: different monomers (1,2-, 1,3-, 1,4-DAB, pyrrole, $o$-anisidine, 1,8-DAN), permeability toward nitrites and other interferences, permselectivty toward nitrites, operational and long-term stability. The best performances were obtained with a poly(1,3-DAB) film and the assembled sensor was characterized morphologically by scanning electron microscope and electrochemically by cyclic voltammetry and amperometry coupled to flow injection analysis (FIA), in terms of linear range of concentration (10-1000 $\mu \mathrm{M})$, limit of detection $(2 \mu \mathrm{M})$, reproducibility (R.S.D.\%: 0.4) and linear regression $(y(\mu \mathrm{A})=1.14 x(\mu \mathrm{M})+2.6)$. Finally real samples (tap and mineral drinking water) were analyzed by adding standard nitrite solutions and the recovery was evaluated showing no matrix effect on sensor performances.

(c) 2006 Elsevier B.V. All rights reserved.
\end{abstract}

Keywords: Electrochemical sensors; Polymeric films; Polymeric nanotubule nets; Permselectivity; Nitrites

\section{Introduction}

The quantitative determination of nitrite concentration is of rapidly increasing interest, especially for the monitoring of drinking water quality and in the food industry when water is often used as a raw material. Nitrite ions are a precursor in the formation of nitrosamines, which have been shown to be carcinogenic [1]. Moreover, nitrites are routinely added to meat products as a preservative against food poisoning microorganisms such as Clostridium botulinum [2]. Furthermore, when nitrites are present at high concentration in blood, they can react with the iron (III) of the haemoglobin, forming methemoglobin, which has no oxygen carrying ability; this disease is called methemoglobinemia or "Blue Baby Syndrome" [3]. For these reasons, nitrite's presence in drinking water must to be limited and in Italy legal limits are fixed at value of $2 \mu \mathrm{M}$ [4].

\footnotetext{
* Corresponding author. Tel.: +3906 72594403.

E-mail address: vanessa.biagiotti@uniroma2.it (V. Biagiotti).
}

Many methods have been reported [5,6] for quantitative determination of nitrite including chromatography, potentiometry and fluorimetry, but nitrites are traditionally determined spectrophotometrically by their reaction with sulphanilamide and $N$-naphthylenediamine (Griess reaction). Nitrites are also electroactive species that are readily oxidized at platinum electrodes polarized at $+900 \mathrm{mV}$ versus $\mathrm{Ag} \mid \mathrm{AgCl}$. Since the potential for nitrite oxidation is high, many other electroactive compounds present in complex media can interfere in the nitrite analysis. Permselective coatings offer the promise of bringing higher selective and stability to electrochemical devices. This is accomplished by exclusion from the surface of unwanted matrix constituents, while allowing transport of the target analyte. Different avenues to control the access to the surface, based on different transport mechanism, have been proposed. These include the use of charged-exclusion coating [7], hydrophobic lipid [8] or alkilthiols layers [9] or size-exclusion polymeric films [10]. Such anti-interference membrane barriers offer an effective separation step in situ on the surfaces and hence protect the surface against adsorption of large macromolecules or minimize overlapping signal from undesired electroactive interference. Size-exclusion 
properties are attributed to the morphology of electropolymerized films [11].

In this work, platinum electrodes were covered by different electropolimerized barriers which have size exclusion properties and which have been synthetized by two different techniques: polymeric films traditionally [12] obtained by cyclic voltammetry and polymeric nanotubule nets obtained by "template synthesis" approach [13]. Permeability toward nitrites and interferences and the correspondent permselectivity were evaluated. For the first time, the influence of the polymer structure on permeability was explained by morphological studies. The best performances were obtained using poly(1,3-DAB) film and poly (1,2-DAB) nanotubule nets in terms of permselectivity and the resulting sensors were characterized to detect nitrites by amperometry in flow injection analysis (FIA). Best analytical performances were obtained modifying the platinum electrode by traditional electropolymerized film and operational and longterm stability, were studied. Real samples (drinking mineral and tap water) were analyzed and recovery studies were performed, showing the absence of matrix effects.

\section{Experimental}

\subsection{Reagents and solutions}

1,2-Diaminobenzene (1,2-DAB), 1,3-diaminobenzene (1,3DAB), 1,4-diaminobenzene (1,4-DAB), $\mathrm{NaNO}_{2}, \mathrm{Na}_{2} \mathrm{SO}_{3}$, phenol and $\mathrm{NaClO}_{4}$ were purchased from Sigma Chemical Co. (St. Louis, MO); 1,8-diaminonaphtalene (1,8-DAN), $o$-anisidine, pyrrole were from Fluka (Buchs, Switzerland); $\mathrm{CH}_{3} \mathrm{COOH}$, $\mathrm{NaH}_{2} \mathrm{PO}_{4}, \mathrm{CH}_{3} \mathrm{COONa}, \mathrm{HCl}, \mathrm{HClO}_{4}, \mathrm{H}_{2} \mathrm{SO}_{4}$, ascorbic acid (AA) and $\mathrm{CH}_{2} \mathrm{Cl}_{2}$ were from Carlo Erba (Milan, Italy). $\mathrm{Pt}$ foils (thickness $0.025 \mathrm{~mm}$ ) were purchased from Sigma-Aldrich and polycarbonate nanoporous particle track-etched membranes (PC nanoPTMs) having a thickness of $10 \mu \mathrm{m}$, a pore density of $1 \times 10^{8}$ pores $/ \mathrm{cm}^{2}$ and pore diameters ranging from 15 to $100 \mathrm{~nm}$, were obtained from Nucleopore (Italy).

\subsection{Apparatus}

An AUTOLAB PGstat/12 potentiostat/galvanostat was used for voltammetric studies and electropolymerizations. The amperometric measurements were carried out with a 641 VADetector (Metrohm, Switzerland) and currents were recorded using a Linseis L6512 recorder (Linseis, Selb, Germany). A Pt-Ag|AgCl|3 M (model 805/CPG/6, from AMEL, Milan, Italy) was used as combined auxiliary/reference electrode, and a platinum electrode (model 492/Pt/3, AMEL, Milan, Italy) represented the working electrode.

For FIA measurements combined with electrochemical detection, we used a wall-jet cell (model 656, Metrohm, Herisau, Switzerland), a peristaltic pump Minipuls 3 (Gilson, France) with a six-way injection valve (model 5020) and a closed loop of $250 \mu \mathrm{l}$ (Rheodyne, USA) and PTFE connection tubes (i.d. $0.5 \mathrm{~mm}$ from Supelco, Bellofonte, CA).

Morphologic studies were carried out at room temperature using a Field Emission Scanning Electron Microscope (model S-4000, Hitachi, Japan) having an accelerating voltage of $20 \mathrm{keV}$.

\subsection{Procedure}

\subsubsection{Electrode polishing}

The platinum electrode surfaces were polished with alumina powder $\left(\mathrm{Al}_{2} \mathrm{O}_{3}\right.$, Buehler, Evanston, IL) having different particle size: $1,0.3$ and $0.05 \mu \mathrm{m}$ before use. After rinsing with distilled water, the electrodes were pre-treated by potential cycling in $0.5 \mathrm{M} \mathrm{H}_{2} \mathrm{SO}_{4}$ from -0.2 to +1.2 versus $\mathrm{Ag} \mid \mathrm{AgCl}$ at a scan rate of $20 \mathrm{mV} / \mathrm{s}$, until no changes were observed in the cyclic voltammograms [12].

\subsubsection{Synthesis of polymeric films}

Traditional polymeric films were synthetized directly on the electrode surface by cyclic voltammetry [14]. All the monomers, except the substituted naphthalene derivative, were used at a concentration of $5 \mathrm{mM}$ and dissolved in $0.1 \mathrm{M}$ phosphate buffer solution at pH 6.5 [15]. Solutions were deoxygenated with $\mathrm{N}_{2}$ for $15 \mathrm{~min}$ just before the electropolymerization experiment. The potential was continuously cycled from 0 to $+0.8 \mathrm{~V}$ (versus $\mathrm{Ag} \mid \mathrm{AgCl}$ ) for 20 scans at a scan rate of $2 \mathrm{mV} / \mathrm{s}$ for 1,2-DAB, 1,3$\mathrm{DAB}, 1,4-\mathrm{DAB}$, pyrrole and $o$-anisidine. 1,8-DAN (5 mM) was electropolymerised in $\mathrm{HCl} 1 \mathrm{M}$. This greater acidity was required for its solubilization presumably because of its higher hydrophobicity. The potential was continuously cycled from -0.15 to $+1.3 \mathrm{~V}$ (versus $\mathrm{Ag} \mid \mathrm{AgCl}$ ) for 20 scans at a scan rate of $2 \mathrm{mV} / \mathrm{s}$.

\subsubsection{Synthesis of polymeric nanotubule nets}

Polymeric nanotubule were produced by the "template synthesis" [13] approach. A metallic Pt foil $\left(1 \mathrm{~cm}^{2}\right)$ has been used as working electrode. The polycarbonate nanoporous particle track-etched membranes were used as a template membrane for the synthesis of polymer nanostructured nets and they were assembled as working electrode in a conventional onecompartment cell on a platinum foil. The electropolymerization was performed, at room temperature using platinum as counter electrode, and an $\mathrm{Ag} \mid \mathrm{AgCl}$ as reference electrode. All the monomers were used at a concentration of $5 \mathrm{mM}$ and dissolved in $0.01 \mathrm{M} \mathrm{HClO}_{4}+0.1 \mathrm{M} \mathrm{NaClO}_{4}$, as supporting electrolyte. Solutions were deoxygenated with $\mathrm{N}_{2}$ for 15 min just before the electropolymerization experiment. Different potentials were applied for $250 \mathrm{~s}$ during the chronocoulometric experiment, depending on the monomer: $0.6 \mathrm{~V}$ for the three diaminobenzene isomers, $0.75 \mathrm{~V}$ for 1,8 -DAN, $0.8 \mathrm{~V}$ for pyrrole and $o$-anisidine. Then, the template was dissolved by dichloromethane and the polymer nanotubules were placed directly on the platinum electrode surface, by drop coating. For the preliminary investigations $50 \mathrm{~nm}$ pore of PC template membrane, were used for all the monomers. Then the pore diameter was varied in order to evaluate the size exclusion effect of the nanostructured polymeric film on nitrite ion permeability.

\subsubsection{Study of permeability and permselectivity}

The permeability toward nitrites and several common interferences such as ascorbic acid, sulfites and phenols, was eval- 
uated by cyclic voltammetry [14]. The potential was cycled between 0.2 and $1.2 \mathrm{~V}$ at scan rate of $20 \mathrm{mV} / \mathrm{s}$. All these analytes were used at a concentration of $40 \mathrm{mM}$, in $0.1 \mathrm{M}$ acetate buffer $\mathrm{pH} 4$ and the oxidation current peaks of nitrite and interferences were compared.

\subsubsection{FIA procedure}

For amperometric measurements in a flow injection analysis (FIA) the optimised parameters were found to be: flow-rate $0.6 \mathrm{ml} / \mathrm{min}$, applied potential $+0.9 \mathrm{~V}$ versus $\mathrm{Ag} \mid \mathrm{AgCl}$, and $0.1 \mathrm{M}$ acetate buffer, $\mathrm{pH} 4$ as carrier solution. Standard nitrite solutions were prepared in $0.1 \mathrm{M}$ acetate buffer $\mathrm{pH} 4$ and then injected into a $250 \mu l$ loop, using a six-way injection valve.

\subsubsection{Operational stability study}

Study of operational stability was carried out by cyclic voltammetry. The potential was cycled between 0.2 and $1 \mathrm{~V}$ at scan rate of $50 \mathrm{mV} / \mathrm{s}$. Two hundred scans were performed in the same day. Nitrite was used at concentration of $40 \mathrm{mM}$, in $0.1 \mathrm{M}$ acetate buffer, $\mathrm{pH} 4$ and the peak currents were recorded.

\subsubsection{Long-term stability study}

A long-term stability study was carried out by cyclic voltammetry. The potential was cycled between 0.2 and $1 \mathrm{~V}$ at scan rate of $50 \mathrm{mV} / \mathrm{s}$. All the analytes were used at concentration of $40 \mathrm{mM}$, in $0.1 \mathrm{M}$ acetate buffer, $\mathrm{pH} 4$ and the peak current were recorded. Each day measurements were performed using fresh solutions. When not in use, the sensor was kept dried at room temperature.

\subsubsection{Recovery studies}

Recovery studies were carried out by amperometry in batch mode using $0.5 \mathrm{M}$ acetate buffer $\mathrm{pH} 5$ to minimize $\mathrm{pH}$ changes in real sample analysis. Buffer $(2 \mathrm{ml})$ was diluted directly in drinking water $(8 \mathrm{ml})$ and spiked by $20-50 \mu \mathrm{M}$ of nitrites.

\section{Results and discussion}

\subsection{Study of permeability}

The goal of this work is to investigate various polymeric barriers that could be used to assemble a sensor that will be highly permeable to nitrite but exclude as much as possible potential interference. For this purpose, in this work study about permeability toward nitrites and some common interferences, was performed. Three target interferents, which can be oxidized at the same working potential, were selected: ascorbic acid (AA), phenol $(\mathrm{PhOH})$ and sulfite. AA represents the most common interferent for application of biosensors field [16]; phenols are toxic substances frequently occurring in the aquatic environments, being generated by petroleum and petrochemical industries. Phenols are considered as priority pollutants to control, since they are harmful to organisms at low concentrations $[17,18]$. Finally, sulfite is a small anion comparable to nitrite and it is commonly used in the food and pharmaceutical industries as preservatives and antioxidants. Sulfite and its
Table 1

Permeability of traditional polymeric films

\begin{tabular}{lcccl}
\hline $\begin{array}{l}\text { Monomers used } \\
\text { for the synthesis } \\
\text { of polymeric films }\end{array}$ & $P \% \mathrm{NO}_{2}{ }^{-}$ & $P \% \mathrm{SO}_{3}{ }^{2-}$ & $P \% \mathrm{PhOH}$ & $\mathrm{P} \% \mathrm{AA}$ \\
\hline 1,2-DAB & 14.5 & 91.3 & 41.9 & 7.24 \\
$1,3-\mathrm{DAB}$ & 25.6 & 2.42 & 3.13 & 0.28 \\
1,4-DAB & 0.910 & 0.0520 & 1.22 & 0.183 \\
$1,8-\mathrm{DAN}$ & 0.620 & 1.63 & 29.4 & 0.490 \\
-Anisidine & 3.02 & 3.60 & 21.5 & 0.220 \\
Pyrrol & 6.06 & 0.762 & 0.524 & 5.84 \\
\hline
\end{tabular}

oxidation products are pollutants and sulfiting agents, in particular, have an allergenic effect on hypersensitive individuals [19].

Film permeability was evaluated measuring the peak current by cyclic voltammetry for each analyte. Then the permeability $(P \%)$ was calculated using the equation (1), as described in [12]:

$P \%=\left(I_{\text {film }} / I_{\text {bare }}\right) \times 100$

where $I_{\text {bare }}$ is the peak current recorded at bare electrode and $I_{\text {film }}$ is the peak current at the modified platinum electrode. Table 1 shows the results obtained for the traditional polymeric films. Among them poly(1,3-DAB) had a good $P \%$ for nitrite while also shows good rejection of interferents. The permeability results obtained for platinum electrodes modified by nanostructured polymeric net are reported in Table 2. Almost all of the films exhibit high permeability toward nitrite, but also toward interferents. A better behaviour was obtained using poly(1,2-DAB) nanotubule net, considering that it represented a compromise between good permeability for nitrite with a significant repulsion of interferents.

\subsection{Study of permselectivity}

Since a film that comparably reduces the response to analyte and potential interferents offers no advantages over a bare platinum electrode, the determination of the permselectivity represents an important factor for evaluation of the sensor performance. It is defined as the ratio between nitrite permeability and interferent permeability, as reported in the Eq. (2):

$P=P \%_{\text {nitrites }} / P \%_{\text {interferences }}$

Table 2

Permeability of polymeric nanotubule nets

\begin{tabular}{lcccc}
\hline $\begin{array}{l}\text { Monomers used for the } \\
\text { synthesis of polymeric } \\
\text { nanotubules nets }\end{array}$ & $\mathrm{PN} \mathrm{NO}_{2}{ }^{-}$ & $\mathrm{P}_{\mathrm{SO}} \mathrm{SO}^{2-}$ & $\mathrm{P} \% \mathrm{PhOH}$ & $\mathrm{P} \% \mathrm{AA}$ \\
\hline 1,2-DAB & 4.05 & 0.790 & 4.28 & 0.390 \\
1,3-DAB & 34.3 & 28.3 & 50.4 & 25.2 \\
1,4-DAB & 65.7 & 59.1 & 83.3 & 20.9 \\
1,8-DAN & 17.1 & 17.7 & 82.1 & 14.7 \\
-Anisidine & 88.8 & 65.1 & 93.9 & 66.8 \\
Pyrrol & 19.8 & 11.7 & 8.5 & 19.2 \\
\hline
\end{tabular}



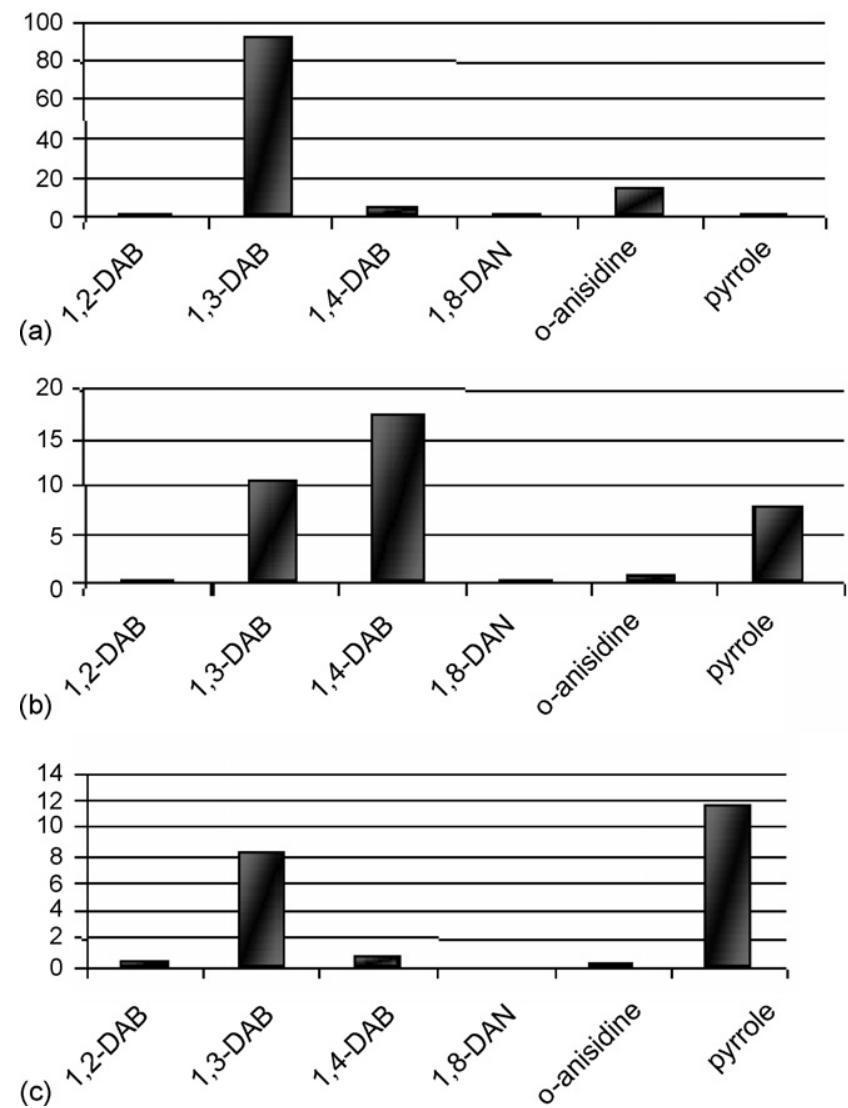

Fig. 1. Permselectivity of traditional polymeric films (a) $P \% \mathrm{NO}_{2}{ }^{-} / P \%$ AA (b) $P \% \mathrm{NO}_{2}{ }^{-} / \mathrm{P} \% \mathrm{SO}_{3}{ }^{2-}$ (c) $P \% \mathrm{NO}_{2}-/ P \% \mathrm{PhOH}$.

\subsubsection{Traditional polymeric films}

Fig. 1 shows results obtained for traditional polymeric films. Poly(1,3-DAB) represents the best polymeric layer in terms of high permeability for nitrite and permselectivity toward all the investigated interferents. In particular the permselectivity of this polymeric film could be explained in terms of its relatively high degree of hydrophobicity, where the oxidation of both amino groups resulted in an extensivly cross-linked and less permeable polymer matrix. In addition the discrimination against electroactive species by charge repulsion represents another means of achieving selectivity, although it is very well known that all the polymeric films except the poly(1,2-DAB) significantly reject acetaminophen, a neutral molecule[20]. Infact, poly(1,3-DAB) showed lower permeability toward negatively charged molecules and the neutral one $(\mathrm{PhOH})$, confirming that in this case, an additional electrostatic repulsion mechanism could act combined to the hydrophobicity and the polymeric chain structure effects, increasing the analytical performances in terms of permselectivity. According to literature [14] poly(1,8-DAN), resulted more hydrophobic than the three isomers of diaminobenzene demonstrating that there is a lower degree of solvatation, a closer packing of the polymer chains, and hence a lower permeability towards all the molecules considered in this work, ever for nitrite. Considering the ratio between the hydrophobicity and the polymer chain structures, poly(1,2-DAB), poly(1,4-DAB), poly $(o$-anisidine $)$ and poly(pyrrole) have only one amino or hydroxyl group involved in the polymer formation and the resulting films are relatively hydrophilic [14]. For this reason a low degree of cross-linking between the polymer chains could be reasonable of a comparable permeability toward nitrite and interferences demonstrating no good performances in terms of permselectivity.

\subsubsection{Polymeric nanotubule net}

Fig. 2 shows the results obtained synthesizing polymeric nanostructures using polycarbonate membrane having $50 \mathrm{~nm}$ pore size. The best performances in terms of permselectivity were obtained using poly(1,2-DAB) nanotubule net. The higher permselectivity values are probably related to denser distribution of these structures that is directly related to an easier process of electropolymerization. Infact small pore sizes of template (nanometer cut-off) play an important role during the monomer diffusion process making easily 1,2-DAB electropolymerization, because only one amino group is involved. This effect is strictly related to poly(1,2-DAB) molecular structure if compared to the other polymers having complex molecular architectures both in terms of the different substituent positions on the aromatic ring (poly (1,3-DAB) and poly $(1,4-$ $\mathrm{DAB})$ ) and a major number of the aromatic rings in the structure (poly(1,8-DAN)). For this purpose, to confirm this hypothesis related to the permselectivity performances of the poly $(1,2-$ $\mathrm{DAB}$ ) nanotubules and their nanostructured morphology, an


Fig. 2. Permselectivity of polymeric nanotubule nets (a) $P \% \mathrm{NO}_{2}-/ P \%$ AA; (b) $P \% \mathrm{NO}_{2}-/ P \% \mathrm{SO}_{3}{ }^{2-}$; (c) $P \% \mathrm{NO}_{2}-/ P \% \mathrm{PhOH}$. 
Table 3

Study of different pore size PC membrane effect on the permeability of poly(1,2DAB) nanotubules nets

\begin{tabular}{lcccc}
\hline $\begin{array}{l}\text { Pore size } \\
\text { diameter }(\mathrm{nm})\end{array}$ & $\mathrm{P}^{2} \mathrm{NO}_{2}{ }^{-}$ & $\mathrm{P}_{\mathrm{SO}}{ }^{2-}$ & $\mathrm{P} \% \mathrm{PhOH}$ & $P \% \mathrm{AA}$ \\
\hline 15 & 50.0 & 14.0 & 44.5 & 57.1 \\
30 & 4.05 & 0.79 & 4.28 & 0.39 \\
50 & 19.1 & 5.78 & 13.1 & 2.51 \\
100 & 13.1 & 5.86 & 10.2 & 8.46 \\
\hline
\end{tabular}

additional study was performed using different pore diameters of polycarbonate membrane during the poly(1,2-DAB) nanotubules growth. The best analytical responses were obtained with nanotubules having $30 \mathrm{~nm}$ of diameter (see Tables 3 and 4) considering a compromise between a good permeability and a good permselectivity, respectively. This nanometer cut-off minimizes the major permeability toward interferences, typical of the largest pore diameter of the template membrane, giving an easier access for the polymer diffusion into the template pores compared to the smaller pore diameter template.

\subsection{Morphological characterization}

The morphology of the electropolimerized films was investigated using a field emission type scanning electron microscope (FE-SEM). Fig. 3a shows poly(1,3-DAB) film synthesized directly on a platinum foil having a thickness of $0.025 \mathrm{~mm}$ and it reveals the presence of the typical globular structure of the electrosynthesized polymers [21]. In any case this nodular arrangement produces a dense and overlapped polymeric film (Fig. 3b), which is probably responsible of the high permeability for nitrite and suitable permselectivity toward all the investigated interferences.

Poly(1,2-DAB) nanotubule nets synthesized by the template method dissolving the membrane in dichloromethane, showed a typical filled cylindrical morphology [22]. This coating provides a larger surface area per unit volume than the electrodeposited polymeric films. So more porous layers were obtained and this is in agreement with high permeability values calculated for these nets.

\subsection{FIA procedure}

Having identified the best microstructured and nanostructured polymeric films synthesized on the probe surface, they were analytically characterized in a FIA analysis system for the amperometric detection of nitrite. Calibration curves for nitrite

Table 4

Study of different pore size PC membrane effect on the permselectivity of poly (1,2-DAB) nanotubules nets

\begin{tabular}{lcll}
\hline $\begin{array}{l}\text { Pore size } \\
\text { diameter }(\mathrm{nm})\end{array}$ & $\begin{array}{l}P \% \mathrm{NO}_{2}{ }^{-} / P \% \\
\mathrm{AA}\end{array}$ & $\begin{array}{l}P \% \mathrm{NO}_{2}{ }^{-} / P \% \\
\mathrm{SO}_{3}{ }^{2-}\end{array}$ & $\begin{array}{l}P \% \mathrm{NO}_{2}-/ P \% \\
\mathrm{PhOH}\end{array}$ \\
\hline 15 & 0.88 & 3.57 & 1.12 \\
30 & 10.4 & 0.95 & 0.68 \\
50 & 7.61 & 3.30 & 1.46 \\
100 & 1.55 & 2.24 & 1.28 \\
\hline
\end{tabular}

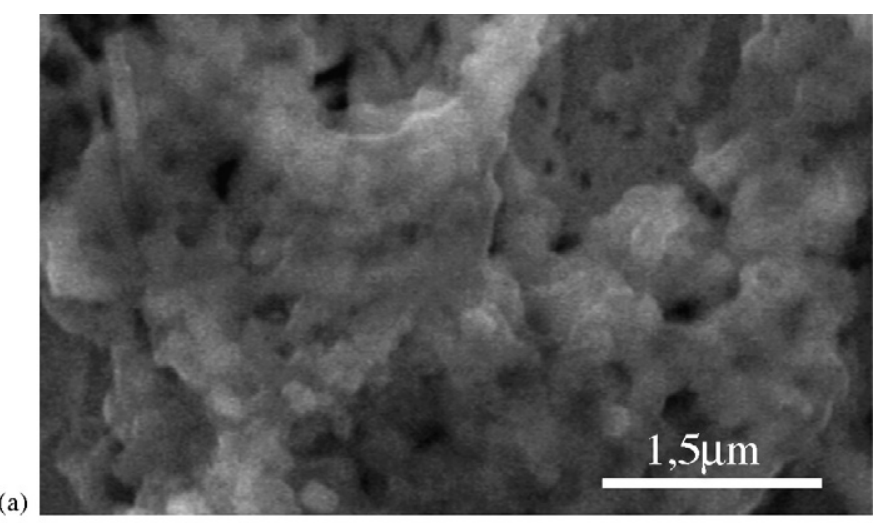

(b)

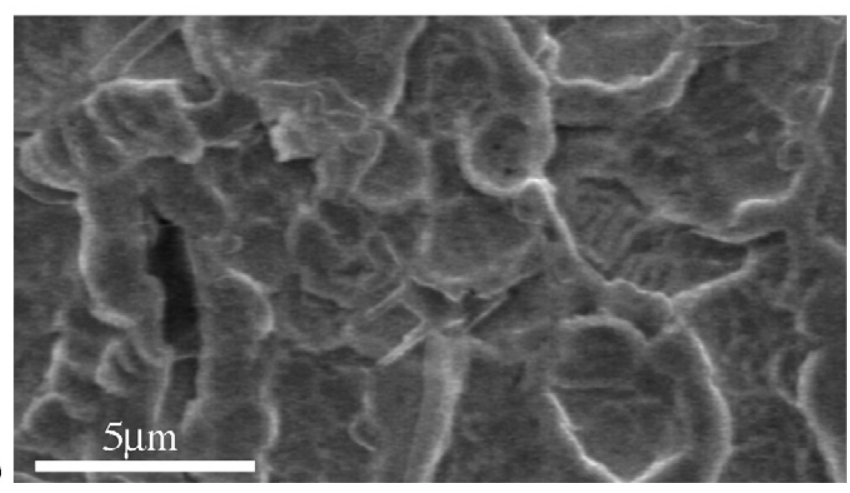

Fig. 3. Poly[1,3-DAB] film grown in $0.1 \mathrm{M}$ phosphate buffer $\mathrm{pH} 6.5$ by cyclic voltammetry $(0-0.8 \mathrm{~V}$ vs. $\mathrm{Ag} \mid \mathrm{AgCl} ; 2 \mathrm{mV} / \mathrm{s} ; 10$ scans $) \mathrm{WE}$ : Pt foil $(0.025 \mathrm{~mm}$ of thickness).

were generated using the two different electrodes in the system and on the basis of these results parameters are summarized in Table 5. The microstructured poly(1,3-DAB) modified platinum electrode could be seem to have good linearity over the range $10-1000 \mu \mathrm{M}$, a linear regression equation of $I(\mu \mathrm{A})=1.14 x$ $(\mu \mathrm{M})+2.6$, and a detection limit $(\mathrm{LOD}=3 \sigma)$ of $2 \mu \mathrm{M}$.

On the other hand the best nanostructured sensor, assembled using poly $(1,2-\mathrm{DAB})$ nets, showed good linearity over the range $10-1000 \mu \mathrm{M}$, a linear regression equation of $I(\mu \mathrm{A})=0.20 x$ $(\mu \mathrm{M})+2.8$ and a detection limit of $2 \mu \mathrm{M}$.

\subsection{Stability studies}

Platinum electrode modified by poly(1,3-DAB) traditional film showed best analytical parameters and its stability was studied. Operational stability was evaluated by doing 200 measurements in a day. All peak current values were referred to the initial value. Fig. 4 shows that the sensor loses $50 \%$ of signal over 100 measurements. It is interesting to note that for the first time, an operational stability study demonstrated reasonable sensor behaviour, working continuously during the same day.

Long-term stability was also evaluated storing the sensor dried when not in use, at room temperature. Fig. 5 shows sensor response toward nitrite and interferents expressed in terms of $I \%$, which is defined in the following equation:

$I \%=\left(I_{n} / I_{a}\right) \times 100$

where $I_{a}$ was the peak current value of nitrite obtained on the first day of measurement, and $I_{n}$ was the peak current 
Table 5

Recovery study performed adding standard solutions of nitrites to different water samples

\begin{tabular}{|c|c|c|c|c|c|}
\hline Water sample & $\begin{array}{l}\text { Nitrites added } \\
(\mu \mathrm{M})\end{array}$ & $\begin{array}{l}\text { Nitrites found } \\
\text { before spiking }(\mu \mathrm{M})\end{array}$ & $\begin{array}{l}\text { Expected } \\
\text { value }(\mu \mathrm{M})\end{array}$ & $\begin{array}{l}\text { Measured } \\
\text { value }(\mu \mathrm{M})\end{array}$ & Recovery \% \\
\hline Tap water & 20 & 0 & 20 & 13 & 65 \\
\hline Tap water & 50 & 0 & 50 & 48 & 96 \\
\hline Mineral water "Perla" & 20 & 0 & 20 & 16 & 80 \\
\hline Mineral water "Perla" & 50 & 0 & 50 & 48 & 96 \\
\hline Mineral water "Sant' Agata" & 20 & 0 & 20 & 17 & 85 \\
\hline Mineral water "Sant' Agata" & 50 & 0 & 50 & 44 & 88 \\
\hline
\end{tabular}

The nitrite sensor was a platinum electrode modifies by microstructured poly(1,3-DAB) film.

Table 6

Analytical parameters obtained by amperometry in flow injection analysis

\begin{tabular}{|c|c|c|c|c|c|c|c|}
\hline Electropolymerized films & Linear range $(\mu \mathrm{M})$ & Slope $(\mu \mathrm{M})$ & R.S.D.\% (slope) & $\operatorname{Bias}(\mu \mathrm{A})$ & R.S.D.\% (bias) & $\begin{array}{l}\text { Number of } \\
\text { measurements }\end{array}$ & $\operatorname{LOD}^{\mathrm{a}}(\mu \mathrm{M})$ \\
\hline Poly(1,3-DAB) film & $10-1000$ & 1.14 & 0.04 & 2.6 & 0.4 & 3 & 2 \\
\hline Poly (1,2-DAB) Nanotubules net & $10-1000$ & 0.20 & 0.09 & 2.8 & 1.5 & 3 & 2 \\
\hline
\end{tabular}

Applied potential: $+900 \mathrm{mV}$ vs. $\mathrm{Ag} \mid \mathrm{AgCl}$. Carrier solution: $0.1 \mathrm{M}$ acetate buffer $\mathrm{pH} 4$

${ }^{\text {a }} \mathrm{LOD}=3 \mathrm{~S} / \mathrm{N}$.

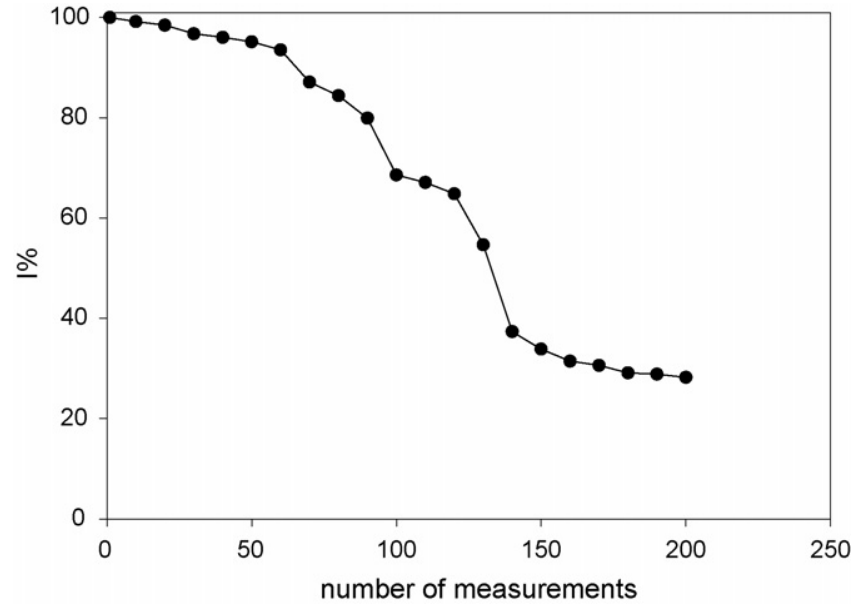

Fig. 4. Operational stability.

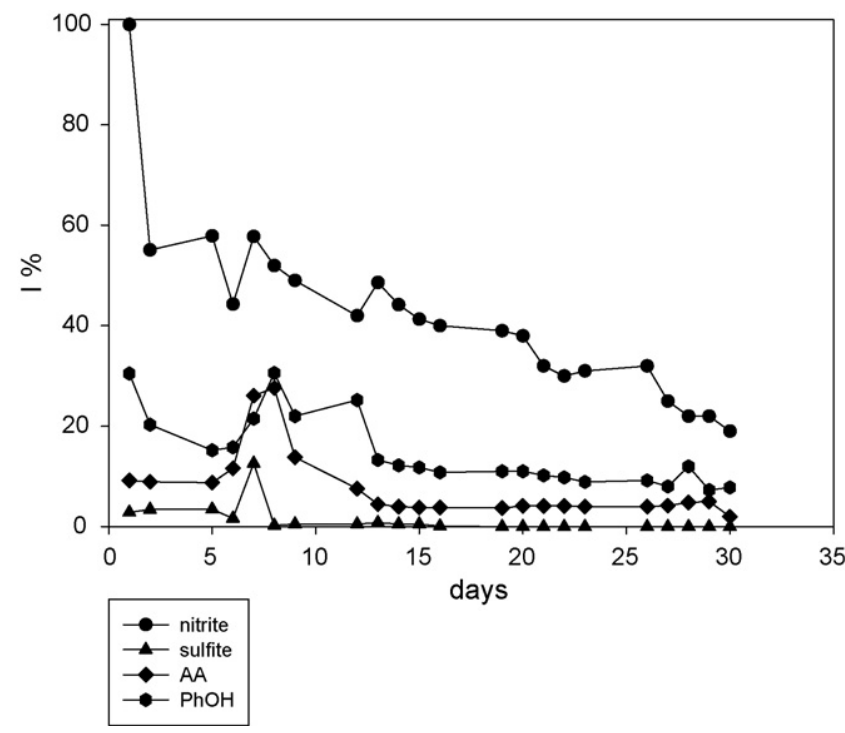

Fig. 5. Long-term stability. value recorded after $n$ days (measuring a solution of $40 \mathrm{mM}$ of nitrite every day). Under these operational conditions, the nitrite sensor it turns out to be stable, since it lost $70 \%$ of the initial signal during 1 month. Considering that a previous study concerning the long-term stability was not reported before in literature, these data could be considered very interesting to evaluate the life time of these sensors under extreme conditions.

\subsection{Recovery study}

Also nitrite recovery data were obtained using a poly $(1,3-$ DAB) film modified platinum electrode. Standard solutions of nitrites were added to different drinking water samples (tap water and two different mineral water, in which no nitrites were present) to obtain final concentrations of 20 and $50 \mathrm{mM}$, respectively. These recovery data reported in Table 6 shows the absence of matrix effect.

\section{Conclusion}

In this paper, platinum electrodes were modified by polymeric barriers synthesized by different techniques to have a selective sensor for nitrite detection. The best resulting sensor was obtained using poly(1,3-DAB) traditional film and it had the sensitivity required for implementation of Italian legal limits for nitrite and there was no demonstrable matrix effect when it was applied for measurements of nitrite in tap and mineral water. The long-term stability of the sensor needs to be improved in order for successful use as a tool for monitoring.

\section{Acknowledgement}

The authors wish to thank the MIUR target project FIRB 2001 no. RBNEOIMBTC-002 for financial support. 


\section{References}

[1] R. Cammack, C.L. Joannou, X. Cui, C. Torres Martinez, S.R. Maraj, M.N. Hughes, Nitrite and nitrosyl compounds in food preservation, Biochim. Biophys. Acta 1411 (1999) 475-488.

[2] H. Yetim, A. Kayacier, Z. Kesmen, O. Sagdic, The effects of nitrite on the survival of Clostridium sporogenes and the autoxidation properties of the Kavurma, Meat Sci. 72 (2006) 206-210.

[3] V.Yu. Titov, Yu.M. Petrenko, Proposed mechanism of nitriteinduced methemoglobinemia, Biochemistry 70 (4) (2005) 473483.

[4] D.P.R. 24 maggio 1988. n. 236 Attuazione della direttiva CEE numero 80/778 concernente la qualità delle acque destinate al consumo umano, ai sensi dell'art. 15 della L. 16 aprile 1987. n. 183 Pubblicato nella Gazzetta Ufficiale 30 giugno 1988 n. 152, S.O. The Italian Official Bullettin.

[5] M.J. Moorcroft, J. Davis, R.G. Compton, Detection and determination of nitrate and nitrite: a review, Talanta 54 (2001) 785-803.

[6] L. Monser, S. Sadok, G.M. Greenway, I. Shah, R.F. Uglow, A simple simultaneous flow injection method based on phosphomolybdenum chemistry for nitrate and nitrite determinations in water and fish samples, Talanta 57 (2002) 511-518

[7] B.A. Deore, H. Shiigi, T. Nagaoka, Pulsed amperometric detection of underivatized amino acids using polypyrrole modified copper electrode in acidic solution, Talanta 58 (2002) 1203-1211.

[8] J. Wang, Z. Lu, Higly stable phospholipid/cholesterol electrode coatings for amperometric monitoring of hydrophobic substances in flowing streams, Anal. Chem. 62 (1990) 826-829.

[9] J. Wang, H. Wu, L. Angnes, On-line monitoring of hydrophobic compounds at self-assembled monolayer modified amperometric flow detectors, Anal. Chem. 65 (1993) 1893-1896.

[10] S.V. Sasso, R.J. Pierce, R. Walla, A.M. Yacynych, Electropolimerized 1,2diaminobenzene as a means to prevent interferences and fouling and to stabilize immobilized enzyme in electrochemical biosensors, Anal. Chem. 62 (1990) 111-1117.

[11] Wang Joseph, Analytical Electrochemistry, VCH Publishers Inc., 1994, pp. 91-92 (Chapter 3).

[12] M. Badea, A. Amine, G. Palleschi, D. Moscone, G. Volpe, A. Curulli, New electrochemical sensors for detection of nitrites and nitrates, J. Electroanal. Chem. 509 (2001) 66-72.

[13] A. Curulli, F. Valentini, S. Orlanducci, M.L. Terranova, C. Paoletti, G. Palleschi, Electrosynthesis of non conventional-polymer nanotubules: a new nanostructured material for analytical applications, Sens. Actuators B 100 (2004) 65-71.

[14] L.J. Murphy, Reduction of interference response at a hydrogen peroxide detecting electrode using electropolymerised films of substituted naphtalenes, Anal. Chem. 70 (1998) 2928-2935.

[15] Y.J. Yuan, S.B. Adeloju, G.G. Wallace, In-situ electrochemical studies on the redox properties of polypyrrole in aqueous solutions, Eur. Pol. J. 35 (1999) 1761-1772.

[16] L. Xiao, J. Chen, C. Cha, Elimination of the interference of ascorbic acid in the amperometric detection of biomolecules in body fluid samples and the simple detection of uric acid in human serum and urine by using the powder microelectrode technique, J. Electroanal. Chem. 495 (2000) 27-35.

[17] F.A. Banat, B. Al-Bashir, S. Al-Asheh, O. Hayajneh, Adsorption of phenol by bentonite, Environ. Pollut. 107 (2000) 391-398.

[18] A. Di Corcia, A. Bellioni, M.D. Madbouly, S. Marchese, Trace determination of phenols in natural waters. Extraction by a new graphitised carbon black cartridge followed by liquid chromatography and re-analysis after phenol derivatization, J. Chromatogr. A 733 (1996) 383-393.

[19] M.H. Pournaghi-Azar, M. Hydarpour, H. Dastangoo, Voltammetric and amperometric detection of sulfite using an aluminium electrode modified by nickel pentacyanosylferrate film. Application to analaysis of some real samples, Anal. Chim. Acta 497 (2003) 133-141.

[20] M.N. Friedemann, S.W. Robinson, G.A. Gerhardt, o-phenilenediaminemodified carbon fiber electrodes for the detection of nitric oxide, Anal. Chem. 68 (1996) 2621-2628.

[21] J.N. Barisci, R. Stella, G.M. Spinks, G.G. Fallace, Characterisation of the topography and surface potential of electrodeposited conducting polymer films using atomic force and electric force microscopies, Electro. Acta 46 (4) (2000) 519-531.

[22] F. Valentini, A. Salis, A. Curulli, G. Palleschi, Chemical reversibility and stable low-potential NADH detection with nonconventional conducting polymer nanotubule modified glassy carbon electrodes, Anal. Chem. 76 (2004) 3244-3248.

\section{Biography}

Vanessa Biagiotti was graduated in Chemistry in the "Tor Vergata" University of Rome, Italy in 2004. Now she works as PhD student in Chemistry Department, were the main field of her scientific work focused on the synthesis of new nanomaterials and their assembling as sensor and biosensor for environmental applications. 